\title{
Eating out of home and its correlates in 10 European countries. The European Prospective Investigation into Cancer and Nutrition (EPIC) study
}

Philippos Orfanos ${ }^{1}$, Androniki Naska' ${ }^{1}$, Dimitrios Trichopoulos ${ }^{2}$, Nadia Slimani $^{3}$, Pietro Ferrari $^{3}$, Marit van Bakel ${ }^{3}$, Genevieve Deharveng ${ }^{3}$, Kim Overvad $^{4}$, Anne Tiønneland ${ }^{5}$, Jytte Halkiær ${ }^{5}$, Maria Santucci de Magistris ${ }^{6}$, Rosario Tumino ${ }^{7}$, Valeria Pala ${ }^{8}$, Carlotta Sacerdote $^{9}$, Giovanna Masala ${ }^{10}$, Guri Skeie ${ }^{11}$, Dagrun Engeset ${ }^{11}$, Eiliv Lund ${ }^{11}$, Paula Jakszyn $^{12}$, Aurelio Barricarte ${ }^{13}$, Maria-Dolores Chirlaque ${ }^{14}$, Carmen Martinez-Garcia ${ }^{15}$, Pilar Amiano ${ }^{16}$, J Ramon Quirós ${ }^{17}$, Sheila Bingham ${ }^{18}$, Ailsa Welch ${ }^{18}$, Elizabeth A Spencer ${ }^{19}$, Timothy J Key ${ }^{19}$, Sabine Rohrmann ${ }^{20}$, Jakob Linseisen ${ }^{20}$, Jennifer Ray ${ }^{21}$, Heiner Boeing ${ }^{21}$, Petra H Peeters ${ }^{22}, \mathrm{H}$ Bas Bueno-de-Mesquita ${ }^{23}$, Marga Ocke ${ }^{23}$, Ingegerd Johansson ${ }^{24}$, Gerd Johansson ${ }^{25}$, Göran Berglund ${ }^{26}$, Jonas Manjer ${ }^{26}$, Marie-Christine Boutron-Ruault ${ }^{27}$, Mathilde Touvier ${ }^{27}$, Françoise Clavel-Chapelon ${ }^{27}$ and Antonia Trichopoulou ${ }^{1, *}$

${ }^{1}$ Department of Hygiene and Epidemiology, University of Athens Medical School, 75 Mikras Asias Street, Athens 1 1527, Greece: ${ }^{2}$ Hellenic Health Foundation, Greece: ${ }^{3}$ Nutrition and Hormones Group, International Agency for Research on Cancer, Lyon, France: ${ }^{4}$ Department of Clinical Epidemiology, Aalborg Hospital, Aarhus University Hospital, Aarhus, Denmark: ${ }^{5}$ Institute of Cancer Epidemiology, Danish Cancer Society, Copenhagen, Denmark: ${ }^{6}$ Department of Clinical and Experimental Medicine, Federico II University, Naples, Italy: ${ }^{7}$ Cancer Registry, Azienda Ospedaliera Civile-MP Arezzo, Ragusa, Italy: ${ }^{8}$ Nutritional Epidemiology Unit, National Cancer Institute, Milan, Italy: ${ }^{9} \mathrm{CPO}-P i e m o n t e$, Torino, Italy: ${ }^{10}$ Molecular and Nutritional Epidemiology Unit, CSPO-Scientific Institute of Tuscany, Florence, Italy: ${ }^{11}$ Institute of Community Medicine, University of Tromsø, Norway:

${ }^{12}$ Department of Epidemiology and Cancer Registry, Catalan Institute of Oncology, Barcelona, Spain: ${ }^{13}$ Public Health Institute of Navarra, Pamplona, Spain: ${ }^{14}$ Epidemiology Department, Murcia Health Council, Spain:

${ }^{15}$ Andalusian School of Public Health, Granada, Spain: ${ }^{16}$ Department of Public Health of Gipuzkoa, Donostia-San Sebastian, Spain: ${ }^{17}$ Public Health \& Health Planning Directorate, Asturias, Spain: ${ }^{18}$ MRC Dunn Human Nutrition Unit, Cambridge, UK \& MRC Centre for Nutritional Epidemiology in Cancer Prevention and Survival, Department of Public Health and Primary Care, University of Cambridge, UK: ${ }^{19}$ Cancer Research UK Epidemiology Unit, University of Oxford, Oxford, UK: ${ }^{20}$ Division of Clinical Epidemiology, German Cancer Research Centre, Heidelberg, Germany: ${ }^{21}$ Department of Epidemiology, German Institute of Human Nutrition, Potsdam-Rehbrücke, Germany: ${ }^{22}$ Julius Center for Health Sciences and Primary Care, University Medical Center Utrecht, The Netherlands: ${ }^{23}$ Cancer Epidemiology Centre for Nutrition and Health, National Institute of Public Health and the Environment, Bilthoven, The Netherlands: ${ }^{24}$ Departments of Odontology/Section of Cardiology and Public Health and Medicine/Section of Nutritional Research, Umeå University, Sweden: ${ }^{25}$ Department of Public Health and Medicine/Section of Nutritional Research, Umeå University, Sweden: ${ }^{26}$ Malmö Diet and Cancer Study, University Hospital, Malmö, Sweden: ${ }^{27}$ Institute Gustave Roussy, E3N-EPIC Group, INSERM, Villejuif, France

Submitted 13 November 2006: Accepted 21 February 2007: First published online 21 June 2007

\begin{abstract}
Objective: To compare the average out-of-home (OH) consumption of foods and beverages, as well as energy intake, among populations from 10 European countries and to describe the characteristics of substantial $\mathrm{OH}$ eaters, as defined for the purpose of the present study, in comparison to other individuals.

Design: Cross-sectional study. Dietary data were collected through single 24-hour dietary recalls, in which the place of consumption was recorded. For the present study, substantial $\mathrm{OH}$ eaters were defined as those who consumed more than $25 \%$ of total daily energy intake at locations other than the household premises. Mean dietary intakes and the proportion of substantial $\mathrm{OH}$ eaters are presented by food group and country. Logistic regression analyses were used to estimate the odds of
\end{abstract}


being a substantial $\mathrm{OH}$ eater in comparison to not being one, using mutually adjusted possible non-dietary determinants.

Setting: Ten European countries participating in the European Prospective Investigation into Cancer and Nutrition (EPIC).

Subjects: The subjects were 34270 individuals, 12537 men and 21733 women, aged 35-74 years.

Results: The fraction of energy intake during $\mathrm{OH}$ eating was generally higher in northern European countries than in the southern ones. Among the food and beverage groups, those selectively consumed outside the home were coffee/tea/ waters and sweets and, to a lesser extent, cereals, meats, added lipids and vegetables. Substantial $\mathrm{OH}$ eating was positively associated with energy intake and inversely associated with age and physical activity. Substantial $\mathrm{OH}$ eating was less common among the less educated compared with the more educated, and more common during weekdays in central and north Europe and during the weekend in south Europe.

Conclusions: Eating outside the home was associated with sedentary lifestyle and increased energy intake; it was more common among the young and concerned in particular coffee/tea/waters and sweets.

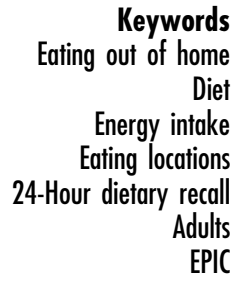

Modern lifestyles and time scarcity have contributed to an increase in food consumption away from home, and the increasing trend is likely to continue ${ }^{1-7}$. The energy and nutrient intakes of individuals who frequently eat at locations other than the household premises (such as restaurants, canteens, cafeterias, fast-food restaurants and similar establishments) may differ from those of individuals who generally eat at home ${ }^{8}$. There have been several studies in the USA and Australia focusing on changes in food and energy intakes related to eating locations ${ }^{1-10}$, but there is a paucity of such studies in European countries ${ }^{11}$.

An additional limitation of the available literature is the lack of a common definition of the eating out of home concept. In general, two main definitions have been used: (1) all food items sourced from external eating locations, irrespective of place of consumption; and (2) all food items consumed at external locations, regardless of whether they were prepared in or outside the home. The use of a common definition would allow direct comparisons of results and would facilitate the formulation of public health policies with the aim to encourage consumers in making healthier dietary choices when eating out?

The objectives of the present study were to assess and compare the average out-of-home $(\mathrm{OH})$ consumption of major foods and beverages, as well as energy intake, among populations from 10 European countries participating in the European Prospective Investigation into Cancer and Nutrition (EPIC) study and to describe the characteristics of those frequently eating out of home in comparison to other individuals.

\section{Subjects and methods}

EPIC is a large prospective cohort study, encompassing about half a million individuals from 10 western European countries, aiming to elucidate the role of dietary, biological, lifestyle and environmental factors in the aetiology of cancer and other chronic diseases. All procedures have been in accordance with the Helsinki Declaration and all participants signed an informed consent form before enrolment. In most centres (but not in all, e.g. Norway, and with harmonised but not identical protocols), the baseline examination, on the day of enrolment, included the completion of detailed dietary, medical history and lifestyle questionnaires, the measurements of anthropometric characteristics and arterial blood pressure and the collection of blood samples. Details on the design and methods of the EPIC study have been presented elsewhere $^{12}$.

In order to adjust for possible systematic over- or underestimation in dietary intake measurements and to correct for attenuation bias in relative risk estimates, a calibration process was utilised. Thus, a single 24-hour dietary recall (24-HDR) was collected from a random sample of $5-12 \%$ of each EPIC cohort, weighted according to the cumulative numbers of cancer cases expected per fixed age and sex stratum ${ }^{13}$.

In total, 36894 individuals from the participating countries provided one 24-HDR between 1995 (study initiated in France) and 2000 (study completed in Norway $)^{13}$. There were several centres in some of the countries, but these were grouped together by country with a single exception: in the Oxford centre (UK), a group of individuals following vegetarian/vegan or other types of presumably healthy diets was evaluated separately ('health-conscious' as contrasted to the 'general population'). In order to maintain the same age range in all the EPIC cohorts, subjects below 35 and over 74 years of age were excluded from the datasets (944 individuals). Of the remaining 35950 participants, 1680 were excluded because of missing information on one or more of the variables of interest in the analyses. Thus, 34270 eligible 
Table 1 Distribution of the study populations by sex and country. The European Prospective Investigation into Cancer and Nutrition (EPIC) Calibration Study 1995-2000

\begin{tabular}{lrrrrrr}
\hline & \multicolumn{2}{c}{ Males } & & \multicolumn{2}{c}{ Females } \\
\cline { 2 - 3 } Country & \multicolumn{1}{c}{$n$} & $\%$ & & $n$ & $\%$ & \\
\hline France & - & - & & 4062 & 100.0 & 4062 \\
Italy & 1394 & 35.9 & & 2494 & 64.1 & 3888 \\
Spain & 1724 & 55.8 & & 1365 & 44.2 & 3089 \\
UK - GP & 315 & 42.2 & & 431 & 57.8 & 746 \\
UK - HC & 81 & 33.5 & & 161 & 66.5 & 242 \\
The Netherlands & 923 & 24.4 & & 2863 & 75.6 & 3786 \\
Greece & 1211 & 48.2 & & 1300 & 51.8 & 2511 \\
Germany & 2264 & 51.5 & & 2133 & 48.5 & 4397 \\
Sweden & 2715 & 45.7 & & 3230 & 54.3 & 5945 \\
Denmark & 1910 & 49.0 & & 1989 & 51.0 & 3899 \\
Norway & - & - & & 1705 & 100.0 & 1705 \\
Total & 12537 & 36.6 & 21733 & 63.4 & 34270 \\
\hline
\end{tabular}

GP - general population; $\mathrm{HC}$ - health-conscious.

individuals from 10 European countries, 12537 men and 21733 women, were included in the present study. The French and Norwegian cohorts included women only and the sex ratio varied considerably among the remaining studied populations. Study participants by sex are shown in Table 1.

\section{Dietary intakes}

The consumption of foods and beverages was recorded by a single 24-HDR, using a highly standardised computerised software, named EPIC-SOFT, that was developed at the International Agency for Research on Cancer (IARC) in collaboration with the EPIC centres. EPIC-SOFT was administered by trained interviewers and included a series of functions and logical structures, in order to ensure the highest possible level of standardisation and lessen the difficulty of the respondents to remember what they had consumed ${ }^{14}$. Information was collected on all foods and beverages consumed by each individual during the time period between waking up on the day of recall and waking up on the following day (interview day).

For the calculation of energy and nutrient intakes the EPIC Nutrient Database (ENDB) was used. In the absence of an existing standardised European nutrient database and as a prerequisite for pooled analyses on an international scale, the ENDB was developed to harmonise nutrient databases across the countries participating in EPIC. Details on the development of ENDB have been published elsewhere ${ }^{15,16}$.

\section{Non-dietary variables}

Data on most of the non-dietary variables were collected at baseline and details on their collection have been published elsewhere ${ }^{13,17,18}$.

Information on education and physical activity was obtained using a self- or interviewer-administered questionnaire $^{17}$. For the purpose of the present analysis, the level of education was classified into four categories: none or primary school completed; technical/vocational school completed; secondary school completed; and university degree. With respect to physical activity, IARC generated two variables: (1) physical activity at work, based on the physical demand of the participant's current profession and classified into sedentary, standing, manual, heavy manual or none, the latter including all individuals who did not work or were retired (data on this variable were not collected in Norway); and (2) physical activity at leisure, expressed as a score, estimated by the sum of products of the time spent on each of several household and recreational activities and the energy cost coefficient of each activity ${ }^{19}$. Sex- and population groupspecific tertiles of the estimated score for physical activity at leisure were then used at IARC, to label physical activity at leisure as minimum, moderate and intense.

With respect to smoking, subjects were classified as: never smokers; former smokers; current smokers of up to 1 pack (20 cigarettes); current smokers of more than 1 pack; and current smokers of unknown number of cigarettes per day.

Anthropometric data were collected both at baseline (measured in most instances) and at the day of the 24HDR interviews (self-reported). These values, however, were highly correlated (overall Spearman correlation coefficient for height, $r=+0.99$; and for weight, $r=+0.97$ ). In the present analysis, body mass index (BMI), relying on weight and height values reported the day of the 24-HDR interview, was used. BMI was estimated as weight $(\mathrm{kg})$ divided by the square of height $(\mathrm{m})$ and participants were classified into four categories according to definitions of the World Health Organization: underweight $\left(\mathrm{BMI}<18.5 \mathrm{~kg} \mathrm{~m}^{-2}\right)$, normal $(\mathrm{BMI} \geq$ 18.5 to $<25 \mathrm{~kg} \mathrm{~m}^{-2}$ ), overweight (BMI $\geq 25$ to $<30 \mathrm{~kg} \mathrm{~m}^{-2}$ ) and obese $\left(\mathrm{BMI} \geq 30 \mathrm{~kg} \mathrm{~m}^{-2}\right)^{20}$. However, because of the small number of individuals in the group of underweight (551), the first two groups were merged (BMI < $25 \mathrm{~kg} \mathrm{~m}^{-2}$ ).

\section{Definitions}

\section{Out-of-home eating}

For each eating (drinking) occasion mentioned in the 24HDRs, the place of consumption was reported. Locations, other than the household premises, included the following: restaurant, friend's house, workplace, cafeteria, bar, fast-food establishment, street, car/boat and other out-of-home places. $\mathrm{OH}$ eating was defined to include consumption of all foods and beverages at any of the aforementioned locations, irrespective of the place of purchase or preparation. This definition has been used previously ${ }^{11,21}$.

\section{Substantial out-of-home eaters}

To identify $\mathrm{OH}$ eaters of substantial quantities, the fraction of a particular food or the energy intake during $\mathrm{OH}$ 
Table 2 Food items/groups included in the main food categories

\begin{tabular}{|c|c|}
\hline Food category & Food items/groups included \\
\hline Potatoes & Potatoes and other tubers \\
\hline Vegetables & $\begin{array}{l}\text { Leafy, fruiting, root, grain and pod vegetables, cabbages, mushrooms, onion and garlic, stalk and sprouts, mixed } \\
\text { salads; all types of legumes }\end{array}$ \\
\hline Fruits & Fruits, fruit salads, nuts and seeds, mixed fruits, olives \\
\hline Dairies & $\begin{array}{l}\text { Milk (liquid or processed), milk beverages, yoghurt, all types of cheese, cream desserts and puddings (milk } \\
\text { based), dairy and non-dairy creams }\end{array}$ \\
\hline Cereals & $\begin{array}{l}\text { Flour, flakes, starches, pasta, rice and other grains, bread, crispbread and rusks, breakfast cereals, salty biscuits, } \\
\text { aperitif biscuits, dough and pastry }\end{array}$ \\
\hline Meats & $\begin{array}{l}\text { Fresh meat (beef, veal, pork, mutton/lamb, horse, goat), poultry (chicken, hen, turkey, duck, goose, rabbit - } \\
\text { domestic), game, processed meat, offals }\end{array}$ \\
\hline Fish & Fish and fish products, fish in crumbs, crustaceans and molluscs \\
\hline $\begin{array}{l}\text { Added lipids } \\
\quad \text { (fats and oils) }\end{array}$ & Vegetable oils, butter, margarines, deep-frying fats, marine oil, other animal fat \\
\hline Sweets & $\begin{array}{l}\text { Sugar, honey, jam, chocolate, candy bars, confectionery non-chocolate, syrup, ice cream, sorbet, cakes, pies, } \\
\text { pastries, puddings (non-milk based), dry cakes and biscuits }\end{array}$ \\
\hline Coffee/tea/waters & Coffee (with or without caffeine), tea (with or without caffeine) and herbal teas, chicory, substitutes, waters \\
\hline $\begin{array}{l}\text { Other non-alcoholic } \\
\text { beverages }\end{array}$ & Fruit and vegetable juices, carbonated/soft/isotonic drinks, diluted syrups \\
\hline Alcoholic beverages & Wine, fortified wines, beer and cider, spirits and brandy, aniseed drinks, liqueurs, cocktails and punches \\
\hline Sauces & $\begin{array}{l}\text { Sauces (tomato sauces, dressing sauces, mayonnaise and similar, dessert sauces), yeast, spices, herbs and } \\
\text { flavourings, condiments }\end{array}$ \\
\hline
\end{tabular}

eating occasions out of the corresponding total was calculated. Substantial $\mathrm{OH}$ eaters of particular food groups were then defined as those individuals receiving at least $25 \%$ of their daily intake of the corresponding food group through eating out. However, in the analysis exploring the determinants of substantial $\mathrm{OH}$ eating, the critical outcome variable was whether study participants consumed (or not) $\geq 25 \%$ of their daily energy intake through eating out.

The information available on substantial $\mathrm{OH}$ eaters concerns a single day, that of the 24-HDR. We have no information about the frequency of $\mathrm{OH}$ eating over time or about the correlation of the quantity of $\mathrm{OH}$ eating between different days of the same person. We have assumed that those who were substantial $\mathrm{OH}$ eaters, as operationally defined, on the particular day of the 24HDR are more likely to be substantial $\mathrm{OH}$ eaters in general than those who were not. The correlation of $\mathrm{OH}$ eating among different days of the same person is likely to be positive but weak, thus entailing considerable misclassification and underestimation of the statistical significance of any association with this variable.

\section{Statistical analyses}

All statistical analyses were performed separately for men and women at the country level (except for Table 4), as well as overall, using the statistical package Intercooled Stata 7.0 for Windows 98/95/NT (Stata Corporation, 2002). The food categories included in this analysis were potatoes and other tubers (subsequently referred to as 'potatoes'), vegetables/legumes (subsequently referred to as 'vegetables'), fruits/nuts (subsequently referred to as 'fruits'), dairy products (subsequently referred to as 'dairies'), cereals/cereal products (subsequently referred to as 'cereals'), meat/meat products (subsequently referred to as 'meats'), fish/shellfish (subsequently referred to as 'fish'), added lipids, sweets (including sugar, confectionery and cakes), non-alcoholic beverages (distinguished into 'coffee/tea/waters' and 'other', essentially soft drinks, which can be sweetened), alcoholic beverages and sauces/condiments (subsequently referred to as 'sauces'). A detailed description of the food items/ groups included in the aforementioned main food categories is given in Table 2 . In order to maximise comparability between countries, population mean intakes (overall, at home and out of home) and corresponding standard errors were calculated adjusting for age and using a set of weights to control for the day (Monday to Thursday, Friday to Sunday) and season (spring, summer, autumn, winter) of the 24-HDRs. The detailed methodology has been described previously ${ }^{13,22}$.

The odds of being a substantial $\mathrm{OH}$ eater (on the basis of total energy intake) in comparison to the odds of not being one were estimated separately for men and women through multiple logistic regression analyses using the following as mutually adjusted possible determinants: the aforementioned non-dietary variables (education, occupational and leisure physical activity, smoking habits and BMI; categorically as previously indicated), age (per 5-year increment; continuously), day of recall (Monday to Thursday, Friday to Sunday; categorically), season of recall (spring, summer, autumn, winter; categorically) and total energy intake (per standard deviation; continuously). Interactions were assessed, when necessary, using the likelihood ratio test ${ }^{23}$.

\section{Results}

Table 3 shows daily intakes of major food groups, as well as energy intake at home and out of home, among men 
Table 3 Daily food and energy intake (at home and out of home) among male and female participants. The European Prospective Investigation into Cancer and Nutrition (EPIC) Calibration Study 1995-2000

\begin{tabular}{|c|c|c|c|c|c|c|c|c|c|c|c|c|c|c|c|c|c|c|c|c|c|c|c|c|c|c|c|c|}
\hline \multirow[b]{3}{*}{ Country } & \multirow{2}{*}{\multicolumn{2}{|c|}{$\begin{array}{c}\begin{array}{c}\text { Potatoes } \\
(\mathrm{g})\end{array} \\
\text { Meant }\end{array}$}} & \multirow{2}{*}{\multicolumn{2}{|c|}{$\frac{\begin{array}{c}\text { Vegetables } \\
(\mathrm{g})\end{array}}{\text { Meant }}$}} & \multirow{2}{*}{\multicolumn{2}{|c|}{$\begin{array}{c}\text { Fruits (g) } \\
\text { Meant }\end{array}$}} & \multirow{2}{*}{\multicolumn{2}{|c|}{$\frac{\text { Dairies }(\mathrm{g})}{\text { Meant }}$}} & \multirow{2}{*}{\multicolumn{2}{|c|}{$\frac{\text { Cereals }(\mathrm{g})}{\text { Meant }}$}} & \multirow{2}{*}{\multicolumn{2}{|c|}{$\frac{\text { Meats }(\mathrm{g})}{\text { Meant }}$}} & \multirow{2}{*}{\multicolumn{2}{|c|}{$\frac{\text { Fish }(\mathrm{g})}{\text { Meant }}$}} & \multirow{2}{*}{\multicolumn{2}{|c|}{$\frac{\begin{array}{c}\text { Added } \\
\text { lipids }(\mathrm{g})\end{array}}{\text { Meant }}$}} & \multirow{2}{*}{\multicolumn{2}{|c|}{$\begin{array}{l}\begin{array}{l}\text { Sweets* } \\
(\mathrm{g})\end{array} \\
\text { Meant }\end{array}$}} & \multirow{2}{*}{\multicolumn{2}{|c|}{$\begin{array}{c}\begin{array}{c}\text { Coffee/tea/ } \\
\text { waters }(\mathrm{ml})\end{array} \\
\text { Meant }\end{array}$}} & \multirow{2}{*}{\multicolumn{2}{|c|}{$\begin{array}{c}\begin{array}{c}\text { Other } \\
\text { non-alcoholic } \\
\text { beverages }(\mathrm{ml})\end{array} \\
\text { Meant }\end{array}$}} & \multirow{2}{*}{\multicolumn{2}{|c|}{$\begin{array}{c}\begin{array}{c}\text { Alcoholic } \\
\text { beverages }(\mathrm{ml})\end{array} \\
\text { Meant }\end{array}$}} & \multirow{2}{*}{\multicolumn{2}{|c|}{$\begin{array}{l}\text { Sauces } \\
(\mathrm{g}) \\
\text { Meant }\end{array}$}} & \multirow{2}{*}{\multicolumn{2}{|c|}{$\begin{array}{c}\begin{array}{c}\text { Energy } \\
\text { (kcal) }\end{array} \\
\text { Meant }\end{array}$}} \\
\hline & & & & & & & & & & & & & & & & & & & & & & & & & & & & \\
\hline & M & $\mathrm{F}$ & M & $\mathrm{F}$ & $\mathrm{M}$ & $\mathrm{F}$ & $\mathrm{M}$ & $\mathrm{F}$ & M & $\mathrm{F}$ & M & $F$ & $M$ & $\mathrm{~F}$ & M & $\mathrm{F}$ & M & $F$ & $M$ & $\mathrm{~F}$ & M & $F$ & $\mathrm{M}$ & $\mathrm{F}$ & M & $F$ & $M$ & $\mathrm{~F}$ \\
\hline \multicolumn{29}{|l|}{ France } \\
\hline At hor & - & 44.0 & - & 190.4 & - & 221.7 & - & 251.8 & - & 136.1 & - & 83.1 & - & 31.4 & - & 17.9 & - & 65.5 & - & 1166.2 & - & 62 & - & 96.7 & - & 21.4 & - & 1665 \\
\hline & - & 10. & - & 324 & - & 30.0 & - & & - & & - & 21.5 & & 8.7 & - & 2.3 & - & & - & & & & & & 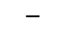 & 63 & - & 340 \\
\hline \multicolumn{29}{|l|}{ Italy } \\
\hline At & 43.9 & 29.6 & 204.2 & 174.4 & 350.0 & 306.2 & 172.6 & 188.4 & 349.6 & 219.6 & 110.3 & 76.6 & 24.5 & 18.6 & 23.0 & 17.1 & 65.1 & 61.2 & 828.4 & 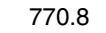 & 42.7 & 32.0 & 251.8 & 6 & 38.2 & 25.3 & 2154.8 & 31569. \\
\hline & 8.0 & 2.7 & .3 & 3.7 & 42.5 & 3 & 9.1 & 14.2 & 64.1 & 28.0 & 20.9 & & 8.2 & 3.9 & 3.3 & 2.3 & 22.7 & 18.0 & 99.3 & & 15 & & 50 & & 6.6 & 3.6 & 441.6 & 5 \\
\hline Spain & & & & & & & & & & & & & & & & & & & & & & & & & & & & \\
\hline & 73.9 & 56.8 & 244.3 & 204.0 & 292.4 & 325.6 & 287.9 & 356.2 & 166.4 & 107.8 & 145.1 & 87.7 & 77.0 & 54.5 & 35.5 & 27.5 & 45.4 & 51 & 703.0 & & & & & & 14.4 & 11.3 & & \\
\hline & & 54 & 283 & & 68.9 & 248 & & & & & 386 & 14.5 & 20.4 & 8.8 & 5.5 & 2.6 & 18.2 & 12 & 00 & & & & & & 22 & 14 & & 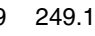 \\
\hline UK - & & & & & & & & & & & & & & & & & & & & & & & & & & & & \\
\hline & 6 & 62.8 & 137.6 & 143.0 & 113.1 & 142.8 & 320.8 & 301.0 & 15 & 122. &  & 61.1 & 25.1 & 23.2 & 25.2 & 16.5 & 97.5 & 73.0 & & & 128 & & & & 2.3 & 32.0 & & 91 \\
\hline & & 9.5 & .3 & 25.7 & 46.2 & 32.3 & 59.4 & & 54.2 & 27 & 9.8 & 15.4 & 8.7 & 6.3 & 10.5 & 4.0 & 36.1 & 27.1 & 368.7 & & 63 & & 41. & 42.7 & 6.9 & 6.2 & 618.5 & (I) \\
\hline JK - & & & & & & & & & & & & & & & & & & & & & & & & & & & & \\
\hline & 3 & 74.9 & 227.3 & 224.0 & 7.8 & 258.7 & .7 & 1 & 23 & 1 & .5 & 12.6 & 1 & 11.2 & 28.5 & 25.2 & 69.8 & 79.1 & 12 & 1 & 1 & 158.9 & 1585 & 3 & 6.2 & 34.8 & 18 & $7 \quad 1701.2$ \\
\hline & & 8.9 & 3.1 & 20.8 & .5 & 5 & 9 & & & & & f & 6 & 2.1 & 3.9 & 2.6 & 19.2 & 13.6 & 23 & & & & 39. & & 2.6 & 3.6 & 265.6 & 6 \\
\hline The I & & & & & & & & & & & & & & & & & & & & & & & & & & & & \\
\hline & 1.6 & 78.0 & 131.0 & 118.1 & 128.0 & 169.5 & 283.3 & 3 & & 1 & 12 & 7 & 14.1 & 9.9 & 33.2 & 21.0 & & 67 & & & & & & & 5.4 & 18.7 & & \\
\hline & & 78 & & & & 0 & & & & & & & & 4.3 & 10.2 & 3.8 & 28.8 & & 34 & & & & & & 4.9 & 3.7 & 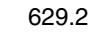 & \\
\hline Gree & & & & & & & & & & & & & & & & & & & & & & & & & & & & \\
\hline & 2 & 29.0 & 27 & 206.5 & 252.3 & 219.5 & 16 & 16 & 24 & 16 & & 42.2 & 45.4 & 25.4 & 42.2 & 31.5 & & & & & 45 & & & 28.5 & 16.3 & 11.1 & & \\
\hline & & 3.5 & & & & & & & & & & 7 & & 60 & 5.8 & 3.6 & & & & & & & & & 3.6 & 21 & & \\
\hline Gerr & & & & & & & & & & & & & & & & & & & & & & & & & & & & \\
\hline & & 63.6 & 13 & 14 & 161.3 & 194.1 & 17 & 19 & & 12 & & 66 & 16.2 & 13.8 & 38.3 & 24.5 & 6 & 69.5 & & & & 16 & & & 26.8 & 21.5 & & \\
\hline & & 12.3 & & 29 & & s & & & & & & 2 & 0 & 38 & 9.1 & 4.0 & & $2 C$ & & & & & & & & 70 & & \\
\hline Swe & & & & & & & & & & & & & & & & & & & & & & & & & & & & \\
\hline & & & & & & & & & & & & & & & & 21 & & & & & & & & & & & & \\
\hline & & & & & & & & & & & & & & & & & & & & & & & & & & & & \\
\hline & & & & & & & & & & & & & & & & & & & & & & & & & & & & \\
\hline & & & & & & & & & & & & & & & 25.7 & 15.0 & & & & & & & & & & & & \\
\hline & .7 & 13.8 & .5 & 6 & 7 & 3 & 4 & 3 &  & 48.9 & 7 & 2 & 1 & 11.2 & 8.7 & 4.4 & 26.9 & 27.3 & 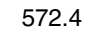 & 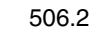 & 67. & 47.7 & 14.5 & 83.8 & 12.0 & 8.4 & 0 & b \\
\hline & & & & & & & & & & & & & & & & & & & & & & & & & & & & \\
\hline & - & 70.1 & - & & - & & 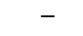 & & - & & - & &  & & - & 14.8 & - & & - & & - & & & & - & - & - & \\
\hline Out & & 94 & - & & - & 37.6 & - & & & & - & 21.0 & & & & 0 & - & 33 & - & & & ( & - & 25 & & 65 & & \\
\hline
\end{tabular}

M - males; F - females; GP - general population; HC - health-conscious

* Sweets included sugar, confectionery and cakes.

t Means adjusted for age, season and day of the week.

Intakes within the household premises.

Intakes at places other than the household (e.g. restaurant, the workplace, cafeteria). 
Table 4 Fractions (in \%) of energy and quantity from the indicated food groups when consumed out of home divided by the corresponding fractions when consumed at home. The European Prospective Investigation into Cancer and Nutrition (EPIC) Calibration Study 1995-2000

\begin{tabular}{|c|c|c|c|c|c|c|c|c|c|c|}
\hline & $\begin{array}{c}\text { Fraction of } \\
\text { energy out } \\
\text { of home* }(\%)\end{array}$ & SD & $\begin{array}{l}\text { Fraction of } \\
\text { energy at } \\
\text { homet (\%) }\end{array}$ & SD & Ratio & $\begin{array}{c}\text { Fraction of } \\
\text { quantity out } \\
\text { of home* }(\%)\end{array}$ & SD & $\begin{array}{l}\text { Fraction of } \\
\text { quantity at } \\
\text { homet (\%) }\end{array}$ & SD & Ratio \\
\hline Potatoes & 1.9 & 5.3 & 3.2 & 5.2 & 0.60 & 1.6 & 4.6 & 2.7 & 4.5 & 0.59 \\
\hline Vegetables & 1.6 & 4.3 & 2.9 & 4.0 & 0.57 & 3.8 & 6.9 & 6.8 & 7.7 & 0.56 \\
\hline Fruits & 7.3 & 17.3 & 7.3 & 9.1 & 1.00 & 6.2 & 14.6 & 8.3 & 9.7 & 0.75 \\
\hline Dairies & 11.2 & 17.0 & 14.8 & 11.7 & 0.75 & 6.4 & 12.5 & 11.8 & 11.5 & 0.54 \\
\hline Cereals & 16.8 & 18.5 & 21.8 & 12.8 & 0.77 & 6.0 & 9.5 & 7.7 & 7.0 & 0.78 \\
\hline Meats & 9.1 & 13.7 & 10.9 & 11.1 & 0.84 & 3.4 & 6.1 & 3.8 & 4.3 & 0.89 \\
\hline Fish & 2.0 & 6.6 & 2.3 & 5.6 & 0.87 & 1.1 & 3.9 & 1.2 & 3.2 & 0.87 \\
\hline Added lipids & 6.3 & 9.2 & 10.6 & 9.2 & 0.60 & 0.8 & 1.5 & 1.2 & 1.3 & 0.66 \\
\hline Sweetsł & 23.7 & 31.5 & 12.3 & 13.4 & 1.92 & 7.2 & 16.4 & 2.9 & 4.0 & 2.50 \\
\hline Coffee/tea/waters & 3.9 & 14.9 & 0.7 & 2.8 & 5.26 & 45.7 & 30.7 & 39.2 & 20.7 & 1.17 \\
\hline Other non-alcoholic beverages & 3.6 & 12.6 & 2.5 & 5.9 & 1.46 & 6.2 & 16.7 & 4.8 & 9.5 & 1.31 \\
\hline Alcoholic beverages & 7.4 & 17.9 & 4.8 & 8.6 & 1.55 & 9.0 & 19.9 & 5.8 & 10.5 & 1.54 \\
\hline Sauces & 2.7 & 6.6 & 3.0 & 5.3 & 0.92 & 0.9 & 2.3 & 1.1 & 2.0 & 0.86 \\
\hline Other (eggs, soups/bouillon, etc.) & 2.4 & 8.3 & 3.0 & 6.3 & 0.79 & 1.6 & 5.8 & 2.8 & 5.8 & 0.60 \\
\hline Total & 100.0 & & 100.0 & & - & 100.0 & & 100.0 & & - \\
\hline
\end{tabular}

SD - standard deviation.

*Intakes at places other than the household premises (e.g. restaurant, the workplace, cafeteria).

tIntakes within the household premises

$\ddagger$ Sweets included sugar, confectionery and cakes.

and women by country. Means adjusted for age, season and day of the week differed little from the crude mean values.

On average, the contribution of $\mathrm{OH}$ eating to the total energy intake of the EPIC participants ranged among men from $12 \%$ in the health-conscious group in the UK to $28 \%$ in Denmark and among women from $11 \%$ in the UK health-conscious group to $28 \%$ again in Denmark. In general, the highest mean values of $\mathrm{OH}$ consumption were recorded in the Scandinavian populations for both men and women. Men reported consuming higher fractions of their total energy intake out of home than did women, except in Sweden and the health-conscious group in the UK where they were similar. Separate tables for men and women (including overall consumption and standard errors) are available online (www.nut.uoa.gr).

We have calculated the fraction (\%) of (1) energy and (2) quantity contributed by the various food groups to respectively total energy and total quantity consumed out of home and at home, and then we divided these fractions to obtain a ratio. Table 4 presents the results. In this table, ratios below 1 indicate that the particular food is, in proportional terms, less frequently consumed out of home than in home. Clearly these ratios vary across centres, genders and age groups and the data shown are crude overall averages. In terms of both energy and quantity, sweets, coffee and tea (on account of the added sugar), alcoholic beverages and other non-alcoholic beverages tend to be over-consumed out of home.

We have operationally defined as substantial $\mathrm{OH}$ eaters those who consumed more than one-quarter of their respective food group (or total energy) out of home on the day of the recall. It is assumed that this variable correlates, although weakly, with $\mathrm{OH}$ eating in general.
Table 5 shows, separately for men and women, the proportion of substantial $\mathrm{OH}$ eaters, as operationally defined, out of the total sample (including those who have not consumed the respective food group), by country. Focusing on total energy intake, the proportion of substantial $\mathrm{OH}$ eaters was generally relatively low in the Mediterranean countries and the health-conscious men in the UK and generally relatively high in the Scandinavian countries. Among the food groups, those selectively consumed out of home were coffee/tea/waters and sweets and, to a lesser extent, cereals, meats, added lipids and vegetables. There were, however, variable patterns among countries.

Table 6 shows, separately for men and women, the ratios of the odds of being a substantial $\mathrm{OH}$ eater with respect to total energy, as operationally defined, vs. the odds of not being one, by specified categories or increments of a series of potentially predictor variables. Odds ratios below the null value of one indicate that the proportion of substantial $\mathrm{OH}$ eaters is lower than that in the referent category and vice versa. Judging the patterns in both sexes together, it was evident that substantial $\mathrm{OH}$ eating tends to be more common in central and northern European countries and less common in Mediterranean countries and among the health-conscious UK residents, particularly men. Substantial $\mathrm{OH}$ eating, as operationally defined, declined consistently with age, among both men and women. Increased energy intake and reduced physical activity (both at work and at leisure) were associated with increased frequency of substantial $\mathrm{OH}$ eating, although the group that included retirees and individuals who for any other reason were not working, were rarely substantial $\mathrm{OH}$ eaters. No association was evident, however, between self-reported BMI and frequency of 
substantial $\mathrm{OH}$ eating, a weak positive trend among women balancing a weak inverse one among men $(P$ for interaction $=0.193)$. No clear pattern emerged in relation to smoking among either men or women, whereas a tendency for less frequent $\mathrm{OH}$ eating during winter was more evident among women. More educated participants were more frequently $\mathrm{OH}$ eaters than less educated ones, but the pattern was not monotonic among men and was inconsistent across centres among women (the pattern being mostly driven by women in Spain and Greece and much less evident in other countries). Overall, the frequency of substantial $\mathrm{OH}$ eating, as operationally defined, was lower during weekends than during weekdays. However, there was significant heterogeneity among countries in that in Mediterranean countries the frequency of substantial $\mathrm{OH}$ eating was higher during the weekends than during weekdays. We repeated this analysis by excluding Friday from the weekend period. The results were qualitatively similar, although in most instances they tended to become more extreme, since eating-out occasions in Friday are for many countries part of the weekly routine, whereas for others (e.g. Mediterranean countries) an opportunity for eating out in the evenings.

\section{Discussion}

In a large study, 34270 adults of both sexes from 10 European countries provided a 24-HDR through a computerised and highly standardised interview. The analysis points to patterns of $\mathrm{OH}$ eating in Europe. Even though measurements refer to a single day and reflect overall patterns modestly at best, there was evidence that the fraction of energy intake during $\mathrm{OH}$ eating was generally higher in northern European countries and generally lower in the southern ones, as well as among the group of health-conscious UK participants. Food groups eaten out of home particularly frequently were coffee/tea/waters and sweets. We have considered as substantial $\mathrm{OH}$ eaters those individuals receiving at least $25 \%$ of their daily energy intake through eating out, under the assumption that individuals who consumed a small fraction of their daily food out of home on a particular day are less likely to be frequent and/or substantial $\mathrm{OH}$ eaters than individuals who reported consuming a relatively large fraction. More men than women belonged in this category. Moreover, we found that young age, sedentary lifestyle and increased energy intake were positive predictors of the probability of substantial $\mathrm{OH}$ eating, among both men and women throughout Europe. Substantial $\mathrm{OH}$ eating, as operationally defined, was less frequent during winter and among the less educated, who were also, as a rule, less well off $^{24}$. Substantial $\mathrm{OH}$ eating was less common during the weekends than in weekdays in western and northern Europe, but more common in southern European countries. 
Table 6 Sex-specific odds ratio (OR), and 95\% confidence interval $(\mathrm{Cl})$, contrasting substantial out-of-home eaters* with others by the indicated variablest. The European Prospective Investigation into Cancer and Nutrition (EPIC) Calibration Study 1995-2000

\begin{tabular}{|c|c|c|c|c|c|c|c|c|}
\hline \multirow[b]{3}{*}{ Age (per 5-year increment) } & \multicolumn{4}{|c|}{ Males $(n=12537)$} & \multicolumn{4}{|c|}{ Females $(n=20028 \ddagger)$} \\
\hline & \multirow{2}{*}{$\frac{\text { OR }}{0.82}$} & \multicolumn{2}{|c|}{$95 \% \mathrm{Cl}$} & \multirow[t]{2}{*}{$P$ for trend } & \multirow{2}{*}{$\frac{\mathrm{OR}}{0.87}$} & \multicolumn{2}{|c|}{$95 \% \mathrm{Cl}$} & \multirow[t]{2}{*}{$P$ for trend } \\
\hline & & 0.79 & 0.84 & & & 0.85 & 0.89 & \\
\hline Body mass index $\left(\mathrm{kg} \mathrm{m}^{-2}\right)$ & & & & 0.290 & & & & 0.320 \\
\hline$<25$ & ref & & & & ref & & & \\
\hline$\geq 25$ to $<30$ & 0.92 & 0.84 & 1.01 & & 1.04 & 0.97 & 1.12 & \\
\hline$\geq 30$ & 0.96 & 0.85 & 1.08 & & 1.04 & 0.94 & 1.15 & \\
\hline Education & & & & 0.424 & & & & $<0.001$ \\
\hline None/primary & ref & & & & ref & & & \\
\hline Technical/vocational & 1.03 & 0.93 & 1.15 & & 1.06 & 0.96 & 1.17 & \\
\hline Secondary & 1.22 & 1.07 & 1.40 & & 1.15 & 1.04 & 1.27 & \\
\hline University degree & 1.01 & 0.91 & 1.14 & & 1.25 & 1.12 & 1.38 & \\
\hline Physical activity at work & & & & $<0.001$ & & & & $<0.001$ \\
\hline $\begin{array}{l}\text { None } \\
\text { Sedentary }\end{array}$ & $\begin{array}{c}0.32 \\
\text { ref }\end{array}$ & 0.29 & 0.36 & & $\begin{array}{l}0.38 \\
\text { ref }\end{array}$ & 0.34 & 0.41 & \\
\hline Standing & 0.88 & 0.79 & 0.98 & & 0.79 & 0.73 & 0.86 & \\
\hline Manual & 0.82 & 0.72 & 0.93 & & 0.72 & 0.63 & 0.82 & \\
\hline Heavy manual & 0.72 & 0.58 & 0.89 & & 0.59 & 0.45 & 0.77 & \\
\hline Physical activity at leisure & & & & 0.045 & & & & $<0.001$ \\
\hline Minimum & ref & & & & ref & & & \\
\hline Moderate & 0.93 & 0.84 & 1.02 & & 0.89 & 0.82 & 0.96 & \\
\hline Intense & 0.91 & 0.82 & 0.99 & & 0.79 & 0.73 & 0.85 & \\
\hline Smoking & & & & 0.642 & & & & 0.367 \\
\hline Never & ref & & & & ref & & & \\
\hline Former & 1.05 & 0.96 & 1.15 & & 1.06 & 0.97 & 1.14 & \\
\hline Current, $\leq 1$ pack & 1.10 & 0.98 & 1.23 & & 1.01 & 0.92 & 1.10 & \\
\hline Current, $>1$ pack & 1.02 & 0.85 & 1.22 & & 1.13 & 0.89 & 1.43 & \\
\hline Current, unknown no. & 0.97 & 0.80 & 1.17 & & 1.08 & 0.74 & 1.58 & \\
\hline Total energy intake (per SD - $787 \mathrm{kcal} \mathrm{day}^{-1}$ ) & 1.17 & 1.13 & 1.21 & & 1.30 & 1.25 & 1.35 & \\
\hline Day of recall & & & & $<0.001$ & & & & 0.011 \\
\hline Monday to Thursday & ref & & & & ref & & & \\
\hline Friday to Sunday & 0.80 & 0.74 & 0.87 & & 0.91 & 0.85 & 0.98 & \\
\hline Season of recall & & & & 0.234 & & & & 0.003 \\
\hline Spring & ref & & & & ref & & & \\
\hline Summer & 1.01 & 0.90 & 1.13 & & 0.97 & 0.88 & 1.06 & \\
\hline Autumn & 1.08 & 0.97 & 1.21 & & 0.92 & 0.84 & 1.00 & \\
\hline Winter & 0.92 & 0.83 & 1.02 & & 0.89 & 0.81 & 0.97 & \\
\hline \multicolumn{9}{|l|}{ Country } \\
\hline Italy & ref & & & & ref & & & \\
\hline France & - & - & - & & 1.25 & 1.09 & 1.43 & \\
\hline Spain & 1.00 & 0.84 & 1.19 & & 0.70 & 0.58 & 0.84 & \\
\hline UK - GP & 2.23 & 1.69 & 2.94 & & 2.32 & 1.83 & 2.94 & \\
\hline $\mathrm{UK}-\mathrm{HC}$ & 0.62 & 0.34 & 1.11 & & 1.44 & 0.99 & 2.07 & \\
\hline The Netherlands & 1.91 & 1.58 & 2.31 & & 1.79 & 1.56 & 2.05 & \\
\hline Greece & 0.91 & 0.75 & 1.11 & & 0.93 & 0.77 & 1.13 & \\
\hline Germany & 2.05 & 1.74 & 2.41 & & 2.02 & 1.75 & 2.34 & \\
\hline Sweden & 2.08 & 1.78 & 2.44 & & 2.96 & 2.59 & 3.39 & \\
\hline Denmark & 2.63 & 2.23 & 3.09 & & 3.13 & 2.70 & 3.62 & \\
\hline
\end{tabular}

SD - standard deviation; GP - general population; HC - health-conscious.

* Substantial out-of-home eaters were defined as those reporting more than $25 \%$ of their total energy intake in out-of-home eating occasions on the day of the recall.

+Variables are mutually adjusted.

$\$ 1705$ Norwegian women are excluded since there were no available data on physical activity at work.

Our results concerning the foods preferentially eaten away from home (including coffee/tea/waters and sweets) are generally similar to those reported previously ${ }^{9,25-28}$, although in some studies in the USA and Australia (but not in our investigation) potatoes were also identified as foods preferred when eating out ${ }^{9,25,28}$. The inverse association of substantial $\mathrm{OH}$ eating with age has also been reported before ${ }^{1,5,9,11,28}$, although the existing data in all studies, including ours, do not allow the distinction between an age-related and an evolving cohortdependent phenomenon. With respect to $\mathrm{OH}$ eating and educational status, the data in our study, as well as in the literature at large ${ }^{1,29}$, are not consistent, possibly because changes in lifestyle have different velocities in different countries and sociodemographic groups.

Increased prevalence of obesity has been linked by several investigators to increased frequency of $\mathrm{OH}$ eating, under the assumption that diets consumed away from home are more energy-rich ${ }^{26,30}$. Our findings and those of others ${ }^{1,5,9,28,31-33}$ that $\mathrm{OH}$ eating is associated with increased energy intake support this view. Also supportive is our finding of an inverse association between 
physical activity and substantial $\mathrm{OH}$ eating, as operationally defined, even though this finding is not consistent in the literature ${ }^{28,33}$. However, we were unable to document an association between BMI and $\mathrm{OH}$ eating in our investigation, a finding that does not contradict the collective evidence from the literature, since positive associations have generally been found among adolescents and young adults, 26,30,34-37 and only rarely among older individuals $^{28,32,38,39}$. It is possible that $\mathrm{OH}$ eating, as operationally defined, is poorly associated with general $\mathrm{OH}$ eating, but we are unable to correct for this misclassification because repeated daily measurements for the same individual were not available. It is also possible that weight and height were incorrectly reported in our investigation and the resulting misclassification attenuates a possible positive association. Another explanation is that $\mathrm{OH}$ eating and the possibly associated increased BMI is a developing phenomenon, which is not adequately captured in a cross-sectional investigation. Finally, it is not possible to exclude that overweight individuals selectively underreport $\mathrm{OH}$ snacking or eating, in an attempt to claim adherence to what are generally perceived as healthier dietary choices ${ }^{40,41}$.

The strengths of this investigation are the large sample size, the coverage of several countries with harmonised protocols, and the investigation of several variables with potential predictive importance. A major limitation of our study, shared by all cross-sectional investigations, is that causal associations have to be inferred, rather than documented, in the absence of demonstrable time sequences. Relying on a single 24-HDR (a prevalence entity) rather than patterns of $\mathrm{OH}$ eating (the more appropriate cumulative incidence entity) is also a limitation. The availability of only one 24-HDR has more serious consequences whenever the intra-individual variability is large compared with the inter-individual variability. Thus, associations may be underestimated, but it is unlikely that significant results would be generated when in reality these do not exist ${ }^{42-44}$. Moreover, mean values cannot be affected by intra-individual random or systematic misclassification, although the corresponding standard deviations (and standard errors) will tend to increase with the degree of random misclassification ${ }^{43-45}$. An additional, but probably minor, limitation is the arbitrariness in operationally defining as substantial $\mathrm{OH}$ eaters those receiving at least $25 \%$ of their daily energy intake through eating out. This arbitrariness could affect the odds ratio estimates, but it is unlikely that it would have generated quantitatively contradictory results if the underlying pattern is monotonic as the empirical evidence suggests it is. Another limitation is that the study population is relatively old and unequally distributed across centres; although controlling for age in the analyses preserves internal validity, the generalisibility, particularly to very young persons, is questionable. Other limitations are the self-reporting of weight and height in the determination of BMI (although these variables are generally correctly reported), comparison of data collected over a 5-year period against the background of an increasing secular trend of $\mathrm{OH}$ eating, and the lack of temporal correspondence between 24-HDRs and some of the evaluated predictor variables. The collective impact of these limitations is likely to be an underestimation of the reported associations.

These arguments rely on the assumption that intraindividual variability of reported intakes is random, an assumption that may not always apply with respect to particular foods ${ }^{46}$. The focus of our investigation, however, is on eating at home or eating out of home - a situation in which systematic errors, particularly when averaged over several individuals, are likely to be less important. Finally, our analyses relied on country-specific samples that were not representative of the corresponding general populations. However, unless the selection factors were strongly associated with eating out of home in ways not explained by the control variables already included in Table 6 (sex, age, education, physical activity, smoking, etc.) distortions are unlikely to be substantial.

In conclusion, we have investigated the pattern of $\mathrm{OH}$ eating in 10 European countries and found evidence that it is associated with sedentary lifestyle and increased energy intake. Eating out of home is particularly common among the young and concerns several food groups, but particularly coffee/tea/waters and sweets. To our knowledge, this is the first European study that compares the frequency and the characteristics of eating out among various European populations. However, additional and preferentially longitudinal work is needed on assessing the relationship of obesity, physical activity or other personal characteristics and lifestyle choices with substantial $\mathrm{OH}$ eating.

\section{Acknowledgements}

Sources of funding: This study was supported by the 'Europe against Cancer' Programme of the European Commission (DG SANCO) for the project EPIC, coordinated by the International Agency for Research on Cancer (World Health Organization); the Greek Ministry of Health and the Greek Ministry of Education (Greece); a fellowship honouring Vasilios and Nafsika Tricha (Greece); the Danish Cancer Society (Denmark); Ligue contre le Cancer (France); Société 3M (France); Mutuelle Générale de l'Education Nationale (France); Institut National de la Santé et de la Recherche Médicale (INSERM) (France); Gustave Roussy Institute and several General Councils in France (France); German Cancer Aid (Germany); German Cancer Research Center (Germany); German Federal Ministry of Education and Research (Germany); Associazione Italiana per la Ricerca sul Cancro (AIRC), Milan (Italy); Associazione Italiana per la 
Ricerca contro il Cancro (AIRC) in Florence (Italy); Compagnia di San Paolo (Italy); Regione Sicilia, Associazione Italiana Ricerca Cancro and Avis-Ragusa (Italy); the Dutch Ministry of Public Health, Welfare and Sports (The Netherlands); the National Cancer Registry and the Regional Cancer Registries of Amsterdam, Utrecht, East and Maastricht (The Netherlands); Health Research Fund (FIS) of the Spanish Ministry of Health (Spain); the Spanish Regional Governments of Andalucia, Asturias, Basque Country, Murcia and Navarra (Spain); the ISCIII Network Red de Centros RCESP (C03/09) (Spain); Swedish Cancer Society (Sweden); Swedish Scientific Council, City of Malmö (Sweden); the Regional Government of Skåne (Sweden); Cancer Research UK (UK); the Medical Research Council (UK); the Stroke Association (UK); the British Heart Foundation; the Department of Health (UK); the Food Standards Agency (UK); the Wellcome Trust (UK); the Norwegian Cancer Society; and the Norwegian Research Council.

The funding sources had no involvement in the study design, in the collection, analysis and interpretation of data, in the writing of the report and in the decision to submit the paper for publication. The author(s) is (are) solely responsible for the publication and the publication does not represent the opinion of the Community. The Community is not responsible for any use that might be made of data appearing in this work.

Conflict of interest declaration: None of the authors has declared a conflict of interest.

Autborship responsibilities: All authors made substantial contribution to conception, design and interpretation of the data, in critically revising the article for important intellectual content, and in finally approving the version to be published.

\section{References}

1 Kant AK, Graubard BI. Eating out in America, 1987-2000: trends and nutritional correlates. Preventive Medicine 2004; 38(2): 243-9.

2 Popkin BM, Haines PS, Siega-Riz AM. Dietary patterns and trends in the United States: the UNC-CH approach. Appetite 1999; 32(1): 8-14.

3 Guthrie JF, Lin BH, Frazao E. Role of food prepared away from home in the American diet, 1977-78 versus 1994-96: changes and consequences. Journal of Nutrition Education and Behavior 2002; 34(3): 140-50.

4 Lin B, Frazao E, Guthrie J. Away-from-home Foods Increasingly Important to Quality of American Diet. Agriculture Information Bulletin No. 749. Washington, DC: US Department of Agriculture, Economic Research Service, 1999; 1-22.

5 Nielsen SJ, Siega-Riz AM, Popkin BM. Trends in energy intake in US between 1977 and 1996: similar shifts seen across age groups. Obesity Research 2002; 10(5): 370-8.

6 Nielsen SJ, Popkin BM. Patterns and trends in food portion sizes, 1977-1998. JAMA: Journal of the American Medical Association 2003; 289(4): 450-3.

7 Jabs J, Devine CM. Time scarcity and food choices: an overview. Appetite 2006; 47(2): 196-204.
8 Roos E, Sarlio-Lahteenkorva S, Lallukka T. Having lunch at a staff canteen is associated with recommended habits. Public Health Nutrition 2004; 7(1): 53-61.

9 Burns C, Jackson M, Gibbons C, Stoney RM. Foods prepared outside the home: association with selected nutrients and body mass index in adult Australians. Public Health Nutrition 2002; 5(3): 441-8.

10 Shrapnel BIS. Fast Food in Australia 1995. Sydney: Shrapnel BIS, 1995.

11 Kearney JM, Hulshof KFAM, Gibney MJ. Eating patterns temporal distribution, converging and diverging foods, meals eaten inside and outside of the home - implications for developing FBDG. Public Health Nutrition 2001; 4(2B): 693-8.

12 Riboli E, Kaaks R. The EPIC project: rationale and study design. European Prospective Investigation into Cancer and Nutrition. International Journal of Epidemiology 1997; 26(Suppl. 1): S6-14.

13 Slimani N, Kaaks R, Ferrari P, Casagrnde C, Clavel-Chapelon $\mathrm{F}$, Lotze $\mathrm{G}$, et al. European Prospective Investigation into Cancer and Nutrition (EPIC) calibration study: rationale, design and population characteristics. Public Health Nutrition 2002; 5(6B): 1125-45.

14 Slimani N, Deharveng G, Charrondiere R, van Kappel AL, Ocke MC, Welch A, et al. Structure of the standardized computerized 24-h diet recall interview used as reference method in the 22 centers participating in the EPIC project. European Prospective Investigation into Cancer and Nutrition. Computer Methods and Programs in Biomedicine 1999; 58(3): 251-66.

15 Slimani N, Deharveng G, Unwin I, Southgate DA, Vignat J, Skeie G, et al. The EPIC Nutrient DataBase project (ENDB): a first attempt to standardise nutrient databases across 10 European countries participating in the EPIC study. European Journal of Clinical Nutrition 2007; in press.

16 Charrondière UR, Vignat J, Møller A, Ireland J, Becker W, Church S, et al. The European Nutrient Database (ENDB) for nutritional epidemiology. Journal of Food Composition and Analysis 2002; 15: 435-51.

17 Riboli E, Hunt KJ, Slimani N, Ferrari P, Norat T, Fahey M, et al. European Prospective Investigation into Cancer and Nutrition (EPIC): study populations and data collection. Public Health Nutrition 2002; 5(6B): 1113-24.

18 Haftenberger M, Schuit AJ, Tormo MJ, Boeing H, Wareham $\mathrm{N}$, Bueno-de-Mesquita HB, et al. Physical activity of subjects aged 50-64 years involved in the European Prospective Investigation into Cancer and Nutrition (EPIC). Public Health Nutrition 2002; 5(6B): 1163-77.

19 James WPT, Schofield EC. Human Energy Requirements: A Manual for Planners and Nutritionists. Oxford: Oxford University Press, 1990.

20 World Health Organization (WHO). Physical Status: The Use and Interpretation of Anthropometry. Report of a WHO Expert Committee. WHO Technical Report Series No. 854. Geneva: WHO, 1995.

21 Gregory J, Foster K, Tyler H, Wiseman M. The Dietary and Nutritional Survey of British Adults. London: HMSO, 1990; 218-27.

22 Agudo A, Slimani N, Ocké MC, Naska A, Miller AB, Kroke A, et al. Consumption of vegetables, fruit and other plant foods in the European Prospective Investigation into Cancer and Nutrition (EPIC) cohorts from 10 European countries. Public Health Nutrition 2002; 5(6B): 1179-96.

23 Lutkepohl H. Introduction to Multiple Time Series Analysis. New York: Springer-Verlag, 1991; Chapter 4.

24 Registar General for England and Wales. Occupational Mortality 1970-1972. OPCS Series DS No. 1. London: Her Majesty's Stationery Office, 1978.

25 Harnack LJ, Jeffery RW, Boutelle KN. Temporal trends in energy intake in the United States: an ecologic perspective. 
American Journal of Clinical Nutrition 2000; 71(6): 1478-84.

26 Bell AC, Swinburn BA. What are the key food groups to target for preventing obesity and improving nutrition in schools? European Journal of Clinical Nutrition 2004; 58(2): 258-63.

27 Le Francois P, Calamassi-Tran G, Hebel P, Renault C, Lebreton S, Volatier JL. Food and nutrient intake outside the home of 629 French people of fifteen years and over. European Journal of Clinical Nutrition 1996; 50(12): 826-31.

28 French SA, Harnack L, Jeffery RW. Fast food restaurant use among women in the Pound of Prevention study: dietary, behavioral and demographic correlates. International Journal of Obesity and Related Metabolic Disorders 2000; 24(10): 1353-9.

29 Haines PS, Hungerford DW, Popkin BM, Guilkey DK. Eating patterns and energy and nutrient intakes of US women. Journal of the American Dietetic Association 1992; 92(6): 698-704, 707.

30 Nielsen SJ, Siega-Riz AM, Popkin BM. Trends in food locations and sources among adolescents and young adults. Preventive Medicine 2002; 35(2): 107-13.

31 Clemens LH, Slawson DL, Klesges RC. The effect of eating out on quality of diet in premenopausal women. Journal of the American Dietetic Association 1999; 99(4): 442-4.

32 McCrory MA, Fuss PJ, Hays NP, Vinken AG, Greenberg AS, Roberts SB. Overeating in America: association between restaurant food consumption and body fatness in healthy adult men and women ages 19 to 80. Obesity Research 1999; 7(6): 564-71.

33 Jeffery RW, French SA. Epidemic obesity in the United States: are fast foods and television viewing contributing? American Journal of Public Health 1998; 88(2): 277-80.

34 Jahns L, Siega-Riz AM, Popkin BM. The increasing prevalence of snacking among US children from 1977 to 1996. Journal of Pediatrics 2001; 138(4): 493-8.

35 Zizza C, Siega-Riz AM, Popkin BM. Significant increase in young adults' snacking between 1977-1978 and 1994-1996 represents a cause of concern! Preventive Medicine 2001; 32(4): 303-10.
36 Gillis LJ, Bar-Or O. Food away from home, sugar-sweetened drink consumption and juvenile obesity. Journal of the American College of Nutrition 2003; 22(6): 539-45.

37 Taveras EM, Berkey CS, Rifas-Shiman SL, Ludwig DS, Rockett HR, Field AE, et al. Association of consumption of fried food away from home with body mass index and diet quality in older children and adolescents. Pediatrics 2005; 116(4): e 518-24.

38 Binkley JK, Eales J, Jekanowski M. The relation between dietary change and rising US obesity. International Journal of Obesity and Related Metabolic Disorders 2000; 24(8): 1032-9.

39 Ma Y, Bertone ER, Stanek 3rd EJ, Reed GW, Hebert JR, Cohen NL, et al. Association between eating patterns and obesity in a free-living US adult population. American Journal of Epidemiology 2003; 158(1): 85-92.

40 Lafay L, Basdevant A, Charles MA, Vray M, Balkau B, Borys $\mathrm{JM}$, et al. Determinants and nature of dietary underreporting in a free-living population: the Fleurbaix Laventie Ville Sante (FLVS) Study. International Journal of Obesity and Related Metabolic Disorders 1997; 21(7): 567-73.

41 Heitmann BL, Lissner L, Osler M. Do we eat les fat, or just report so? International Journal of Obesity and Related Metabolic Disorders 2000; 24(4): 435-42.

42 Armitage P, Berry G. Statistical Methods in Medical Research, 3rd ed. Oxford: Blackwell, 1994.

43 Willett WC. Nature of variation in diet. In: Willett WC, ed. Nutritional Epidemiology, 2nd ed. New York: Oxford University Press, 1998; 33-49.

44 Willett WC. Correction for the effects of measurement error. In: Willett WC, ed. Nutritional Epidemiology, 2nd ed. New York: Oxford University Press, 1998; 302-20.

45 Buzzard M. 24-Hour dietary recall and food record methods. In: Willett WC, ed. Nutritional Epidemiology, 2nd ed. New York: Oxford University Press, 1998; 50-67.

46 Ferrari P, Slimani N, Ciampi A, Trichopoulou A, Naska A, Lauria C, et al. Evaluation of under- and overreporting of energy intake in the 24-hour diet recalls in the European Prospective Investigation into Cancer and Nutrition (EPIC). Public Health Nutrition 2002; 5(6B): S1329-45. 